\title{
Photosynthetic efficiency of apples under protected shade nets
}

\author{
Héctor Olivares-Soto ${ }^{1,3}$, and Richard M. Bastías ${ }^{2 *}$ \\ ${ }^{1}$ Instituto Nacional de Investigaciones Forestales, Agrícolas y Pecuarias (INIFAP), Campo Experimental Tecomán, Colima, \\ México. \\ ${ }^{2}$ Universidad de Concepción, Facultad de Agronomía, Av. Vicente Méndez 595, Chillán, Chile. \\ *Corresponding author (ribastias@udec.cl). \\ ${ }^{3}$ Universidad de Concepción, Facultad de Agronomía, Programa de Doctorado en Ciencias de la Agronomía, Av. Vicente Méndez \\ 595, Chillán, Chile.
}

Received: 12 October 2017; Accepted: 7 December 2017; doi:10.4067/S0718-58392018000100126

\begin{abstract}
Sunburn in apples is caused by excessive solar radiation and high temperatures. Shade netting is used to control sun damage in apple (Malus domestica Borkh.) orchards. The physiological aspects of the effectiveness of this technique have not yet been fully understood. The objective was to study the variation in chlorophyll fluorescence in apples exposed to environmental conditions of radiation and temperature under netting, to better understand the physiological aspects in the effectiveness of this technique to control sun damage. From 50 and up to 150 $\mathrm{d}$ after flowering (DAF), maximum photochemical quantum efficiency of photosystem II $\left(\mathrm{F}_{\mathrm{v}} / \mathrm{F}_{\mathrm{m}}\right)$, incidence of photosynthetically active radiation (PAR, $\mu \mathrm{mol} \mathrm{m} \mathrm{m}^{-2} \mathrm{~s}^{-1}$ ), and fruit surface temperature (FST, ${ }^{\circ} \mathrm{C}$ ) were evaluated in netted and non-netted 'Fuji' and 'Gala' apple orchards with $20 \%$ shade netting, as well as at harvest in fruit picked from the tree. Netting reduced sunburn by $9 \%$ for 'Gala' and 5\% for 'Fuji'. For 'Gala', netting reduced FST from 2 to $5{ }^{\circ} \mathrm{C}$ and 2 to $3{ }^{\circ} \mathrm{C}$ for 'Fuji' compared to the control $(P<0.05)$. The PAR decreased by $27 \%$ for 'Gala' and $22 \%$ for 'Fuji' compared to the control $(P<0.05)$. The mean value of $\mathrm{F}_{\mathrm{v}} / \mathrm{F}_{\mathrm{m}}$ was $12 \%$ in 'Gala' and 3\% in 'Fuji' lower than under netting. This difference in $\mathrm{F}_{\mathrm{v}} / \mathrm{F}_{\mathrm{m}}$ was maintained in fruit picked from the tree and was $13 \%$ in ' $\mathrm{Gala}$ ' and $8 \%$ in 'Fuji'. The effectiveness of nets as a measure to control sun damage in apples is related to the ability of this technique to reduce the photo-inhibition process on the fruit skin.
\end{abstract}

Key words: Sun damage, shade netting, fruit skin photo-inhibition, Malus domestica.

\section{INTRODUCTION}

Sunburn in apples (Malus domestica Borkh.) is a physiological disorder caused by excess solar radiation and high temperatures, and this problem has become more evident in recent years because of the effects of global warming (Schrader et al., 2009). This damage is the most important physiological disorder affecting apples in Chile (Yuri et al., 2004) and other semiarid fruit-producing areas worldwide (Naschitz et al., 2015) as well in some cool environments as North Eastern USA (Brunner et al., 2003). Symptoms include discoloration of the peel with a pale yellowish brown hue in sun-exposed areas of the fruit. These symptoms are induced by both high incidental solar radiation and high temperatures during the growing season of the fruit that cause stress in fruit tissue (Naschitz et al., 2015).

Three types of sunburn have been characterized in apples: Sunburn with necrosis, sunburn with browning on the peel (Schrader et al., 2009), and photo-oxidative damage (Felicetti and Schrader, 2009a). The first type is characterized by damage on the peel caused by exposure to extremely high temperatures $\left(52{ }^{\circ} \mathrm{C}\right)$ that can cause epidermal cell death in the fruit within 10 min (Felicetti and Schrader, 2009b). The second type of damage is 
produced by the joint action of high temperatures and fruit exposure to ultraviolet-B (UV-B) radiation; in this case, browning is noticeable on the peel $2 \mathrm{~d}$ after exposure (Racsko and Schrader, 2012). Photo-oxidative damage develops in fruit that grow under shade conditions and are suddenly exposed to direct light (Zupan et al., 2014). Unlike the first two types of damage, photo-oxidative sunburn occurs under conditions of high levels of photosynthetically active radiation (PAR) because the ultraviolet light spectrum is not usually involved in this type of damage (Felicetti and Schrader, 2009b; Racsko and Schrader, 2012).

There is still discussion as to the temperature threshold that induces sun damage in apples. Wand et al. (2008) found that, depending on duration, 42 to $47^{\circ} \mathrm{C}$ on the fruit peel were fundamental in inducing sunburn symptoms in apples cultivated in South Africa. Likewise, and depending on the cultivar, 46 to $49{ }^{\circ} \mathrm{C}$ were necessary to promote sunburn in apples cultivated in Washington, USA (Schrader et al., 2009). Yuri et al. (2004) reported that apples exposed for $5 \mathrm{~h}$ at $45^{\circ} \mathrm{C}$ is enough to induce sun damage under the climatic conditions in Chile.

From the physiological point of view, it has been determined that the fruit peel exposed to direct sunlight causes photo-inhibition of the photosystem II, expressed as a decrease in the maximum photochemical quantum efficiency of photosystem II $\left(\mathrm{F}_{\mathrm{v}} / \mathrm{F}_{\mathrm{m}}\right)$ in fruit exposed to sun (Ma and Cheng, 2003).

On the other hand, when apple temperature levels are greater than $45{ }^{\circ} \mathrm{C}$, this significantly reduces $\mathrm{F}_{\mathrm{v}} / \mathrm{F}_{\mathrm{m}}$ (Wand et al., 2008). Ma and Cheng (2003) reported that sun-exposed apple tissue exhibited lower photochemical efficiency, but a larger xanthophyll cycle pool size, which indicated the higher thermal dissipation on sun-exposed peel as complementary protective mechanism to mitigate the damage by excess energy. Likewise, it has been demonstrated that the shaded area of the fruit does not adapt to high solar radiation; therefore, it is more sensitive to photoinhibition with $\mathrm{F}_{\mathrm{v}} / \mathrm{F}_{\mathrm{m}}$ values that are lower than the sun-exposed tissue under the same light and fruit development conditions (Li and Cheng, 2008).

Protecting fruit from exposure to solar radiation greatly reduces the appearance of sunburn in apples (Schrader, 2011). Orchard shade netting coverage is used for this purpose; it allows decreasing sunlight and temperature of the fruit surface and lessens direct solar radiation transmission (Dussi et al., 2005). Netting color and density significantly affect direct solar radiation transmission. Blanke (2009) found that sunlight transmission through transparent netting was $95 \%$, while black netting was $78 \%$. In addition to reduced transmitted incident solar radiation, the light spectrum was altered under netting; for example, green and red-colored netting transmit 3\% more green and red light, respectively, without altering the far-red/red relationship (Solomakhin and Blanke, 2010). Amarante et al. (2011) described a decrease from $8 \%$ to $25 \%$ in photosynthetic radiation under different types of netting. Gindaba and Wand (2005) stated that the fruit surface temperature of apples under shade netting was 5 to 9 ${ }^{\circ} \mathrm{C}$ lower on days with maximum air temperature of 34 to $37^{\circ} \mathrm{C}$, respectively. When the air temperature at noon was 30 to $32{ }^{\circ} \mathrm{C}$, fruit surface temperature was $5{ }^{\circ} \mathrm{C}$ lower on the average than apples in the control treatment without shade netting (Gindaba and Wand, 2008). However, the effectiveness of netting to control sun damage in apples has displayed erratic behavior; when evaluated in different geographic locations and varieties, the physiological aspects that determine such differences have not been fully understood (Gindaba and Wand, 2005; Amarante et al., 2011; Umanzor et al., 2017).

The aim of the present research was to study the variation in chlorophyll fluorescence in fruit exposed to environmental conditions of radiation and temperature encountered in orchards under netting to better understand the physiological aspects behind the effectiveness of this technique to control sun damage in apples.

\section{MATERIALS AND METHODS}

\section{Plant material and experimental design}

The experiments were conducted in the Experimental Station "El Nogal" (36³6’21" S; 7206'13" W), Universidad de Concepción, Chillán, Biobío Region, in apple orchards with Gala and Fuji cultivars; these were 4-yr old trees grafted on M9 rootstocks and planted at a distance of $3.5 \times 1 \mathrm{~m}$. Once pollination was completed (fruit set), plots of 40 trees were covered with pieces of $185 \mathrm{~m}^{2}$ of nets, placed at $2.5 \mathrm{~m}$ from the ground. Red and pearl colored nets at $20 \%$ shade (ChromatiNet, Polysack Industries, Negev, Israel), which are commercially used by apple growers, were utilized for 'Gala' and 'Fuji', respectively. Uncovered trees were used as a control. The experiment had a completely 
randomized block design with three replicates (plots) distributed in two rows with north-south orientation for each replicate, and five trees were randomly selected in each plot as the experimental unit.

\section{Evaluation of fluorescence and micro-climatic conditions}

Ten sun-exposed fruits were randomly chosen from the five selected trees of each replicate; fruits were located in the south-west position of the trees at a height of $140 \mathrm{~cm}$ from the soil. At 50, 80, and $110 \mathrm{~d}$ after flowering (DAF) for 'Gala' and 90,120, and $150 \mathrm{DAF}$ for 'Fuji', the following parameters were measured at three moments during the day $\left(10: 00,13: 00\right.$, and 16:00 h): Maximum photochemical quantum efficiency of photosystem II $\left(\mathrm{F}_{\mathrm{v}} / \mathrm{F}_{\mathrm{m}}\right)$, photosynthetically active radiation (PAR, $\mu \mathrm{mol} \mathrm{m} \mathrm{m}^{-2} \mathrm{~s}^{-1}$ ) and fruit surface temperature (FST, ${ }^{\circ} \mathrm{C}$ ). Complementary ultraviolet radiation-B (UV-B W m${ }^{-2}$ ) was measured at $80 \mathrm{DAF}$. The $\mathrm{F}_{\mathrm{v}} / \mathrm{F}_{\mathrm{m}}$ measurements were taken after adapting the fruit skin to darkness for $30 \mathrm{~min}$ with a movable shutter clip (Figure 1). The fluorometer probe was inserted into the hole in the clip; after $0.8 \mathrm{~s}$ exposure for a white light saturation pulse ( 3000 photons $\left.\mathrm{mol} \mathrm{m}^{-2} \mathrm{~s}^{-1}\right)$, maximum $\left(\mathrm{F}_{\mathrm{m}}\right)$ and minimum $\left(\mathrm{F}_{0}\right)$ chlorophyll fluorescence values were quantified with a portable fluorometer (OS5p+, OptiSciences, Hudson, New Hampshire, USA). This information allowed the quantification of $F_{v} / F_{m}$ by the following relationship: $F_{v} / F_{m}=\left(F_{m}-F_{0}\right) / F_{m}$ (Maxwell and Johnson, 2000). At the same time, the incidence of PPFD was quantified with a quantum sensor (LI-189; LI-COR, Lincoln, Nebraska, USA), UV-B radiation measurements with a UV meter (MU-200, Apogee Instruments, Logan, Utah, USA) and FST with an infrared thermometer (Extech, Nashua, New Hampshire, USA) at a distance of $0.2 \mathrm{~m}$ between the fruit and the sensor (Umanzor et al., 2017).

\section{Evaluation at harvest}

At harvest, total fruit from the five trees of each replicate was visually classified for the incidence of sun damage in accordance with a scale developed by Yuri et al. (2004): Healthy fruit (no apparent damage), slight damage (epidermal area with pale yellow coloring), and severe damage (epidermal area with brown coloring and lenticular damage); quantity of damaged fruit was expressed as a percentage. At the same time, 30 healthy fruit from each cultivar were taken to determine the dynamics of photo-inhibition on the fruit peel on a completely sunny day. The 30 fruits were picked from the trees and placed at ground level in trays under netted and non-netted conditions. Small pieces of nets, approximately $2 \mathrm{~m}^{2}$, were placed on a designed model of $1 \mathrm{~m}$ wide by $2 \mathrm{~m}$ long, which simulates the netting installation structure in the orchard (Figure 2). At five moments during the day (10:00, 12:00, 14:00, 16:00, and 18:00 h), maximum $\left(\mathrm{F}_{\mathrm{m}}\right)$ and minimum $\left(\mathrm{F}_{0}\right)$ chlorophyll fluorescence values were quantified with a portable fluorometer $(\mathrm{OS} 5 \mathrm{p}+)$. This information allowed the quantification of $\mathrm{F}_{\mathrm{v}} / \mathrm{F}_{\mathrm{m}}$ by the previously described relationship, as well as the incidence of PPFD with a quantum sensor (LI-189; LI-COR, Lincoln, Nebraska, USA) and FST with an infrared thermometer (Extech) at a distance of $0.2 \mathrm{~m}$ between the fruit and the sensor.

Figure 1. Details of the method developed to measure chlorophyll fluorescence parameters in apple fruit skin using a movable shutter clip under field conditions.

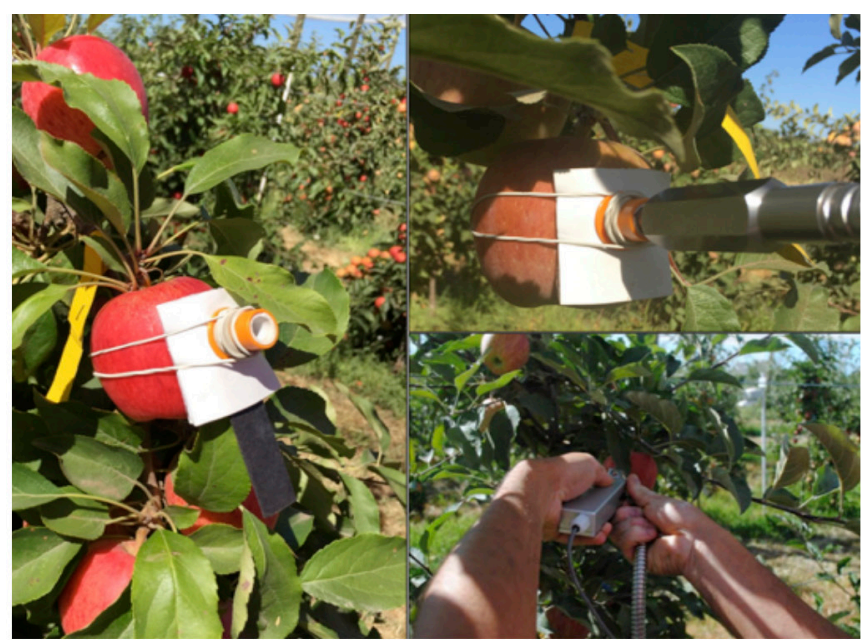


Figure 2. Details of method used to study the netting effects on picked apple fruits.

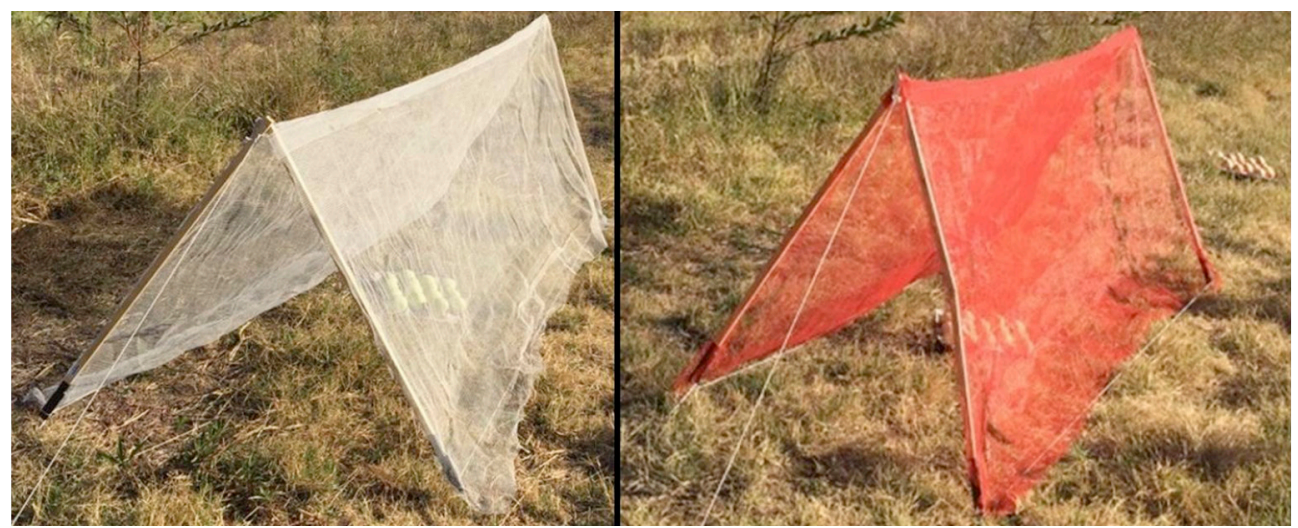

\section{Statistical analysis}

The ten data obtained in each block were subjected to ANOVA at a $P<0.05$ level of significance. Values, expressed as a percentage, were normalized by the $\arcsin \sqrt{ }(x / 100)$ formula. The Pearson correlation coefficient was performed with a significance level of $(P<0.05)$. All the analyses were performed with the SAS (Version 9.1; SAS Institute, Cary, North Carolina, USA) statistical software. Linear regression analyses were performed with Numbers (Numbers IOS 10, Apple Inc., Cupertino, California, USA) with a significance level of $P<0.05$.

\section{RESULTS}

Netting significantly reduced the quantity of sunburn-damaged fruit for both evaluated cultivars. Fruit sunburn incidence in cvs. Gala and Fuji exhibited differences $(P<0.05)$ in the three categories defining damage; incidence in the non-netted control was higher (Figure 3). On the average, netting reduced sunburn by $9 \%$ for 'Gala' and 5\% for 'Fuji'.

The intensity of PAR radiation measured as the active photosynthetic photon flux density (PPFD) shows differences between netted and non-netted treatments $(P<0.05)$. The PPFD was higher in the non-netted control for both cultivars. However, light transmission capacity was variable during the different periods of fruit development for both cultivars. For 'Gala', netting reduced the mean quantity of PPFD transmitted during the day by $29 \%$ at 50 DAF, (Figure 4A), 26\% at 80 DAF, and 29\% at 110 DAF (Figures 4B and 3C). Similar results were observed for

Figure 3. Fruit sunburn incidence for netted and non-netted (control) 'Gala' and 'Fuji' apple trees according to damage category: Healthy, slight, and severe.

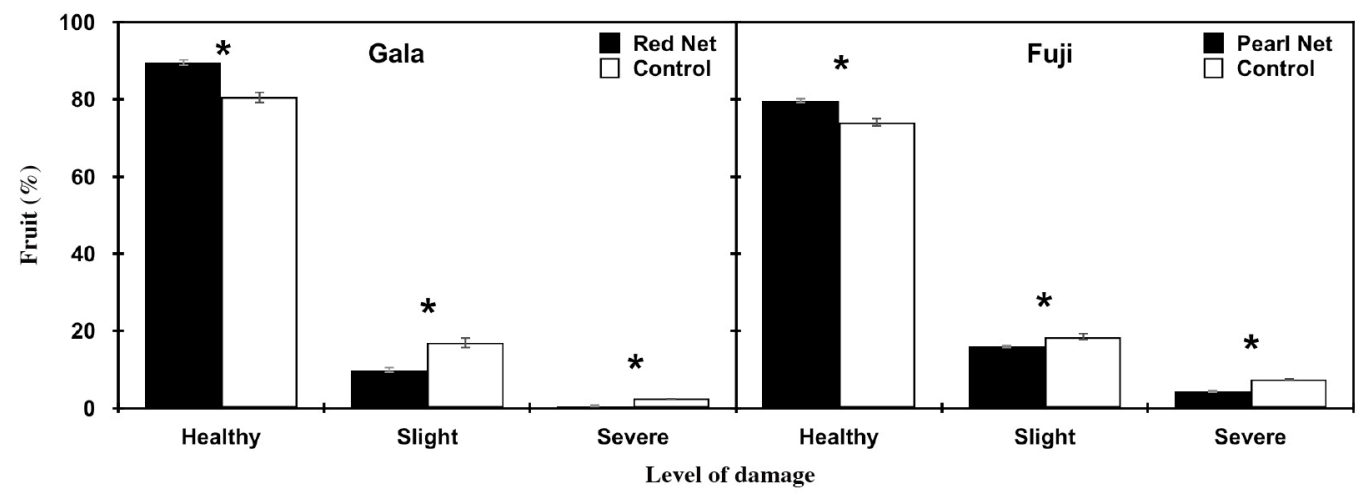

*Significant at the 0.05 probability level. 
Figure 4. Solar radiation as photosynthetic photon flux density (PPFD) measured at 50 (A), 80 (B), and 110 (C) days after flowering (DAF) for netted and non-netted (control) 'Gala' apple trees and 90 (D), 120 (E), and 150 (F) DAF for netted and non-netted (control) 'Fuji' apple trees.

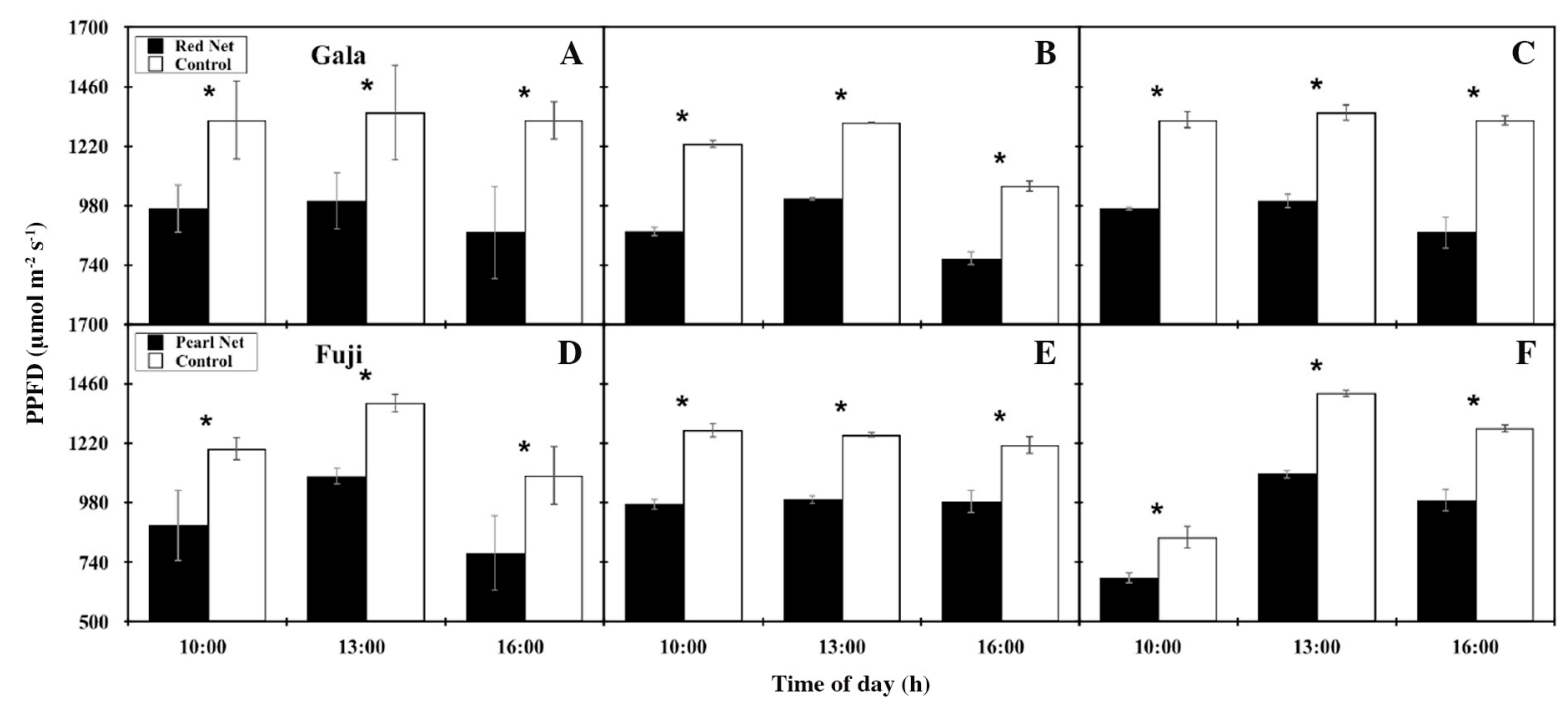

*Significant at the 0.05 probability level.

'Fuji' at 90, 120, and 150 DAF. At 90 DAF, netting reduced the daily mean quantity of transmitted PPFD by $24 \%$, while at 120 and $150 \mathrm{DAF}$ this reduction was $21 \%$ (Figures 4D, 4E y 4F).

The ultraviolet radiation-B (UV-B) intensity shows differences between netted and non-netted treatments $(P<0.05)$. Although UV light transmission was nonsignificantly affected by color of nets, red netting reduced by $5 \%$ more the UV radiation than pearl net (Figure 5).

The FST also exhibited significant differences between netted and non-netted treatments $(P<0.05)$. The FST for 'Gala' was lower with netting compared to the control for all three evaluation periods of 50, 80, and $110 \mathrm{DAF}$ (Figures 6A, 6B, 6C); the most significant differences $(P<0.05)$ occurred at midday $(13: 00 \mathrm{~h})$ and during the afternoon $(16: 00 \mathrm{~h})$. In this cultivar and for these moments during the day, FST was $5{ }^{\circ} \mathrm{C}$ lower under netting compared to the control. 'Fuji'exhibited the same trend as 'Gala' for FST. In this cultivar also revealed significant differences $(P<0.05)$ at midday $(13: 00 \mathrm{~h})$ at 90,120 and $150 \mathrm{DAF}$ and in the afternoon $(16: 00 \mathrm{~h})$ at 90 and $150 \mathrm{DAF}$ (Figures $6 \mathrm{D}, 6 \mathrm{E}, 6 \mathrm{~F})$. However, daily FST in this cultivar was on the average $2{ }^{\circ} \mathrm{C}$ lower under netting compared to the control.

Figure 5. Ultraviolet radiation ( $\left.\mathrm{W} \mathrm{m}^{-2}\right)$ measured at netted and non-netted (control) in 'Gala' and 'Fuji' apple orchards.

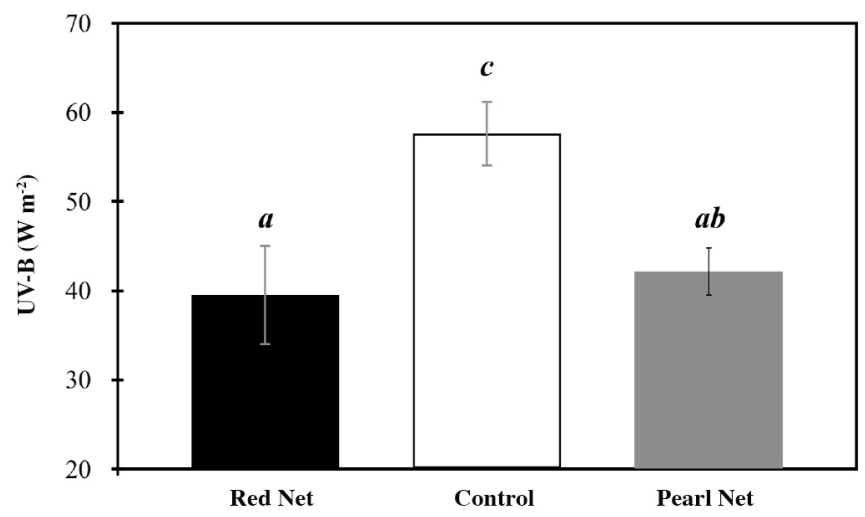

Different lower-case letters indicate significant differences to Tukey's test $(P<0.05)$. 
Figure 6. Fruit surface temperature measured at 50 (A), 80 (B), and 110 (C) days after flowering (DAF) for netted and non-netted (control) 'Gala' apple trees and 90 (D), 120 (E), and 150 (F) DAF for netted and non-netted (control) 'Fuji' apple trees.

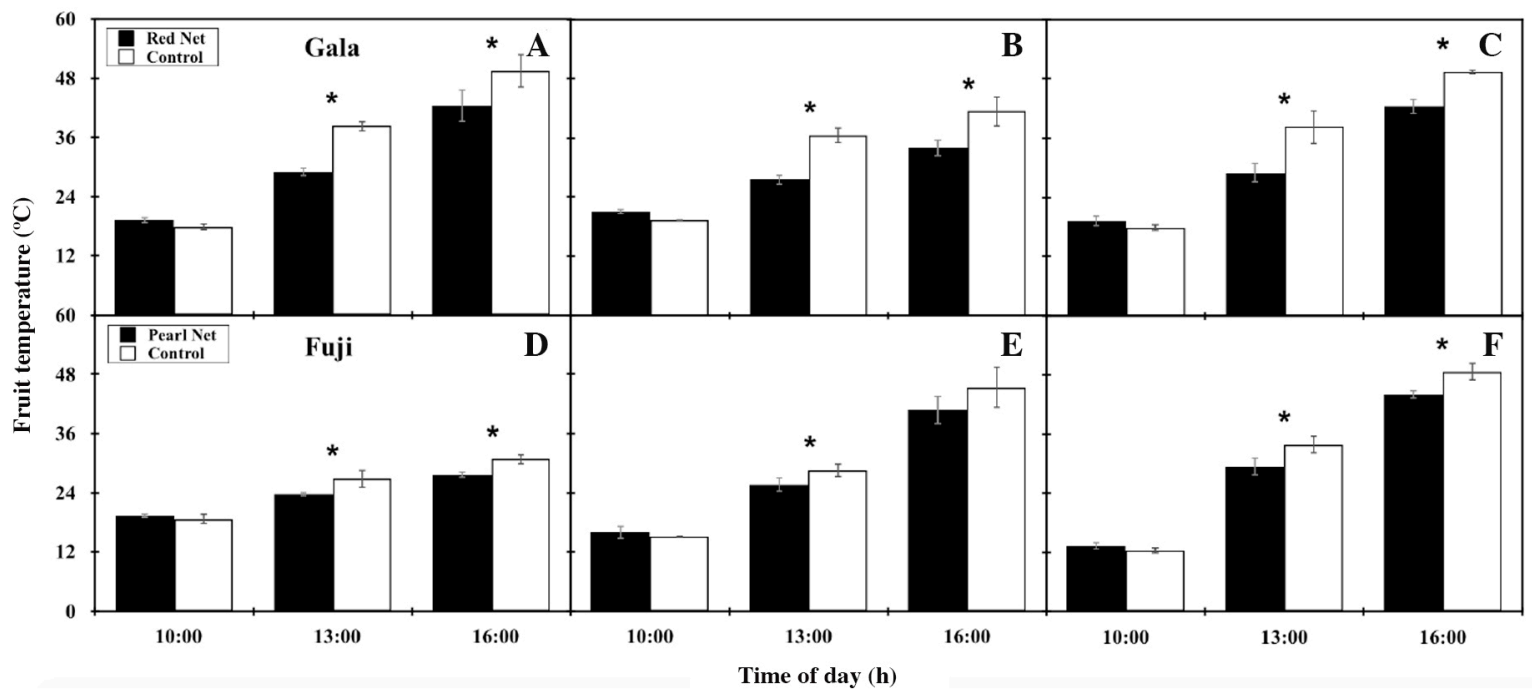

*Significant at the 0.05 probability level.

Maximum photochemical quantum efficiency of photosystem II $\left(\mathrm{F}_{\mathrm{v}} / \mathrm{F}_{\mathrm{m}}\right)$ measured on fruit peel is was also significantly affected during the different fruit growth stages. 'Gala' $\mathrm{F}_{\mathrm{v}} / \mathrm{F}_{\mathrm{m}}$ values at $50 \mathrm{DAF}$ were 0.70 under netting and 0.63 for the control (no netting). In the case of fruit analyzed at $80 \mathrm{DAF}$, the mean daily value of $\mathrm{F}_{\mathrm{v}} / \mathrm{F}_{\mathrm{m}} \mathrm{was}$ 0.70 under netting and 0.60 in the control (Figures 7A, 7B). It should be noted that, for ' $G a l a$ ', it was not possible to estimate the variations in $\mathrm{F}_{\mathrm{v}} / \mathrm{F}_{\mathrm{m}}$ in the fruit with a growth period of 110 DAF probably because in this moment apple peel showed changes in the color development by increasing in red color (anthocyanin) and decreasing in green color (chlorophyll). It can be indicated that the value of $\mathrm{F}_{\mathrm{v}} / \mathrm{F}_{\mathrm{m}}$ in this cultivar under non-netted conditions (control) revealed values that were on the average $12 \%$ lower than the fruit under netting. However, these differences in 'Fuji'

Figure 7. Maximum photochemical quantum efficiency of photosystem II $\left(F_{v} / F_{m}\right)$ measured on the fruit skin at 50 (A) and 80 (B) days after flowering (DAF) for netted and non-netted (control) 'Gala' apple trees and 90 (C), 120 (D), and 150 (E) DAF for netted and non-netted (control) 'Fuji' apple trees.

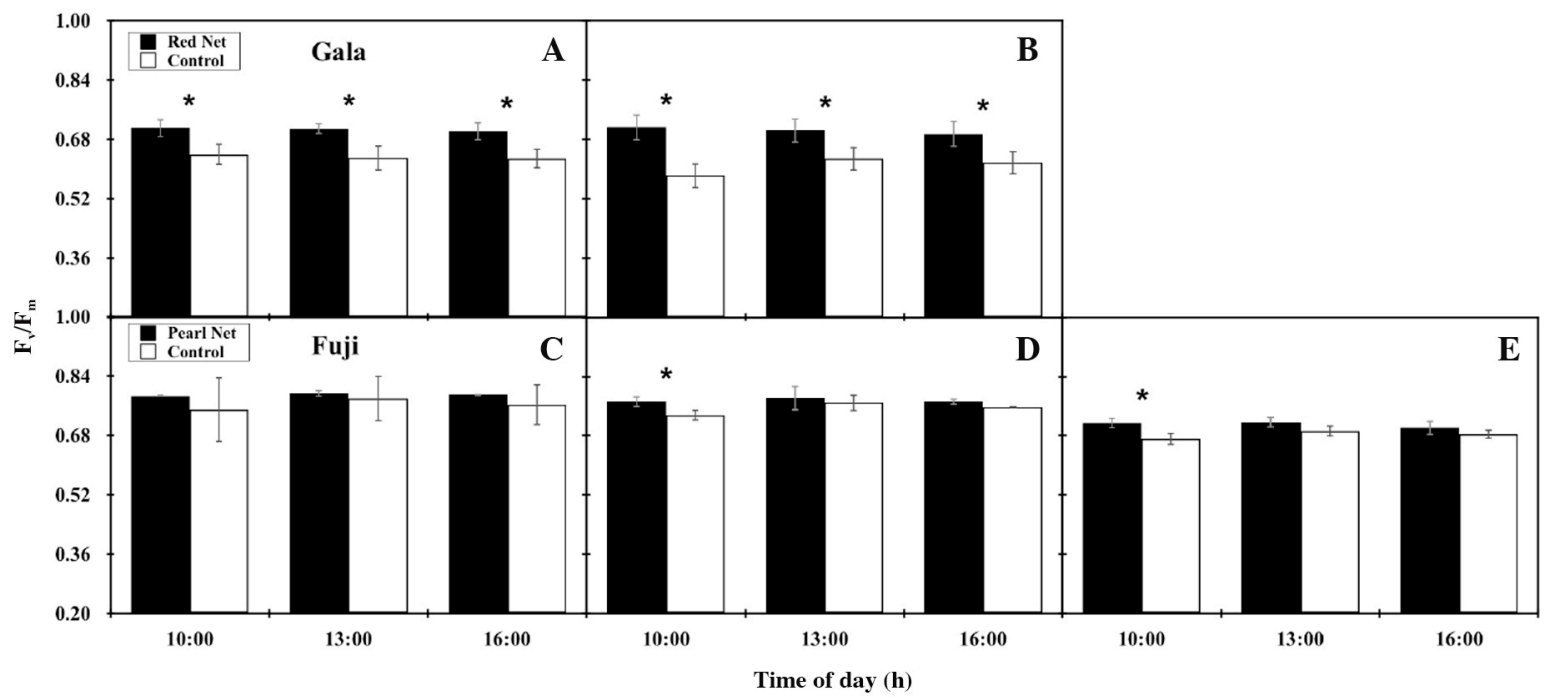

*Significant at the 0.05 probability level. 
were less noticeable than for 'Gala'. At $90 \mathrm{DAF}$, values of $\mathrm{F}_{\mathrm{v}} / \mathrm{F}_{\mathrm{m}}$ in the fruit for this cultivar under netting had a mean of 0.78 compared to 0.76 for the control. Later at $120 \mathrm{DAF}, \mathrm{F}_{\mathrm{v}} / \mathrm{F}_{\mathrm{m}}$ values were recorded with a mean of 0.77 and 0.75 under netting and the control, respectively. Finally, at $150 \mathrm{DAF}$, the $\mathrm{F}_{\mathrm{v}} / \mathrm{F}_{\mathrm{m}}$ mean value recorded under netting was 0.71 compared to 0.68 in the control (Figures $7 \mathrm{C}, 7 \mathrm{D}, 7 \mathrm{~F}$ ). The mean values of $\mathrm{F}_{\mathrm{v}} / \mathrm{F}_{\mathrm{m}}$ in the control in this cultivar were $3 \%$ lower than under netting.

This trend was maintained when the effect of netting was evaluated on mature fruit picked from the trees and sun-exposed for a full day. Netting decreased the mean of PPFD transmission by $15 \%$ (Figure 8A) and FST by $4{ }^{\circ} \mathrm{C}$ (Figure $8 \mathrm{~B}$ ) for 'Gala'. In this case, the $\mathrm{F}_{\mathrm{v}} / \mathrm{F}_{\mathrm{m}}$ value in the non-netted exposed fruit was $13 \%$ lower than with netting (Figure 8C). Although netting reduced the daily PPFD transmission value on the average by 27\% (Figure 9A) and $3{ }^{\circ} \mathrm{C}$ in FST (Figure 9B) in 'Fuji', the $\mathrm{F}_{\mathrm{v}} / \mathrm{F}_{\mathrm{m}}$ value of the non-netted sun-exposed fruit was only $8 \%$ lower compared to the netted treatment (Figure $8 \mathrm{C}$ ).

By performing a Pearson correlation analysis $(P<0.05)$ of the previously described variables, we can perceive that the variation in $F_{v} / F_{m}$ values for 'Gala' was inversely related to the variation in the quantity of PPFD, thus revealing a decreasing trend as the quantity of PPFD increases $\left(\mathrm{R}^{2}=0.6 ; P<0.05\right)$ (Figure 10A). This relationship was not found when the data from the mature fruit picked from the tree were analyzed; in this case, the relationship between $\mathrm{F}_{\mathrm{v}} / \mathrm{F}_{\mathrm{m}}$ and PPFD showed an $\mathrm{R}^{2}$ of 0.16 (Figure 10C), which was nonsignificant $(P>0.05)$.

Figure 8. Daily evolution of solar radiation as photosynthetic photon flux density (PPFD), fruit skin surface temperature, and maximum photochemical quantum efficiency of photosystem II $\left(\mathbf{F}_{\mathrm{v}} / \mathbf{F}_{\mathrm{m}}\right)$ measured at physiological maturity of fruit picked from netted and non-netted (control) 'Gala' apple trees.

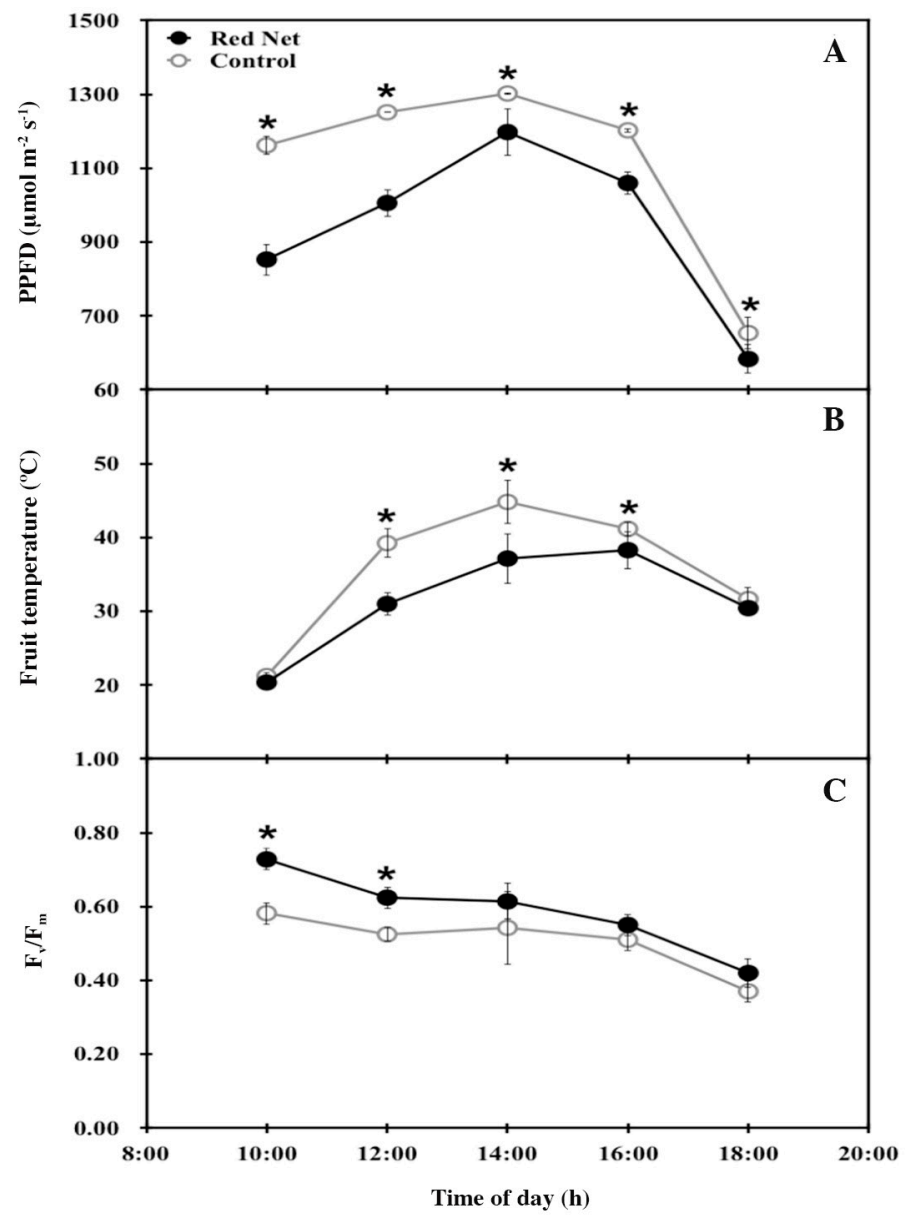

*Significant at the 0.05 probability level. 
Figure 9. Evolution of solar radiation as photosynthetic photon flux density (PPFD), fruit skin surface temperature, and maximum photochemical quantum efficiency of photosystem II $\left(\mathbf{F}_{\mathrm{v}} / \mathbf{F}_{\mathrm{m}}\right)$ measured at physiological maturity of fruits picked from netted and non-netted (control) 'Fuji' apple trees.

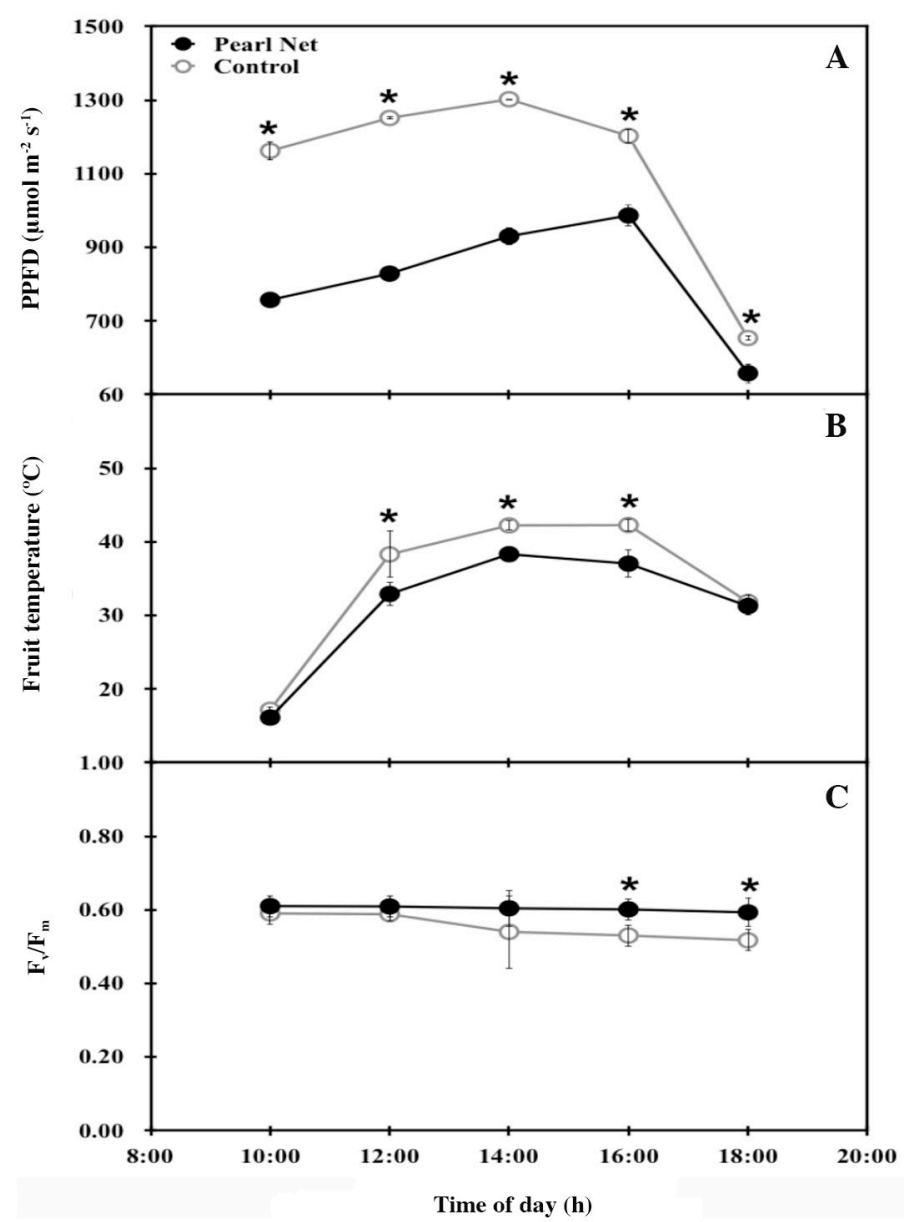

*Significant at the 0.05 probability level.

Nonsignificant relationship $(P>0.05)$ was perceived for 'Fuji' between $\mathrm{F}_{\mathrm{v}} / \mathrm{F}_{\mathrm{m}}$ and the intensity of PPFD radiation (Figure 10B) for both the different fruit growth periods and mature fruit picked from the tree. The correlation between $\mathrm{F}_{\mathrm{v}} / \mathrm{F}_{\mathrm{m}}$ and FST for both varieties (Figure 11) exhibited $\mathrm{R}^{2}$ values that were nonsignificant $(P>0.05)$. This occurred for evaluations of fruit in the tree as well as those picked from the tree.

\section{DISCUSSION}

The determination of climatic thresholds for the occurrence of sun damage and its relationship with changes in chlorophyll fluorescence in fruit is difficult to analyze in orchards. Most reported research is based on studies conducted under laboratory conditions; few studies of this type are under field conditions. More research studies have been developed in others horticultural species such as tomato, cucumber, pepper, melon and cucumber, but without studies in apples (Naschitz et al., 2015). Our study is based on the evaluation and monitoring of micro-climatic variables and chlorophyll fluorescence in fruit growing under netting and field conditions. The amount of severely damaged fruit was less than 10\% (Figure 3), being in 'Fuji' where a greater amount of fruit with severe damage was observed, which indicates the greater sensitivity of 'Fuji' to sun damage (Amarante et al., 2011). The low amount of fruit with severe sun damage registered in both cultivars could be explained by FST reached in ours experiments, 
Figure 10. Relationship between maximum photochemical quantum efficiency of photosystem II $\left(F_{v} / F_{m}\right)$ and solar radiation as photosynthetic photon flux density (PPFD) measured in the growing season (A and B) and at physiological maturity (C and D) for netted and non-netted (control) 'Gala' and 'Fuji' fruit.

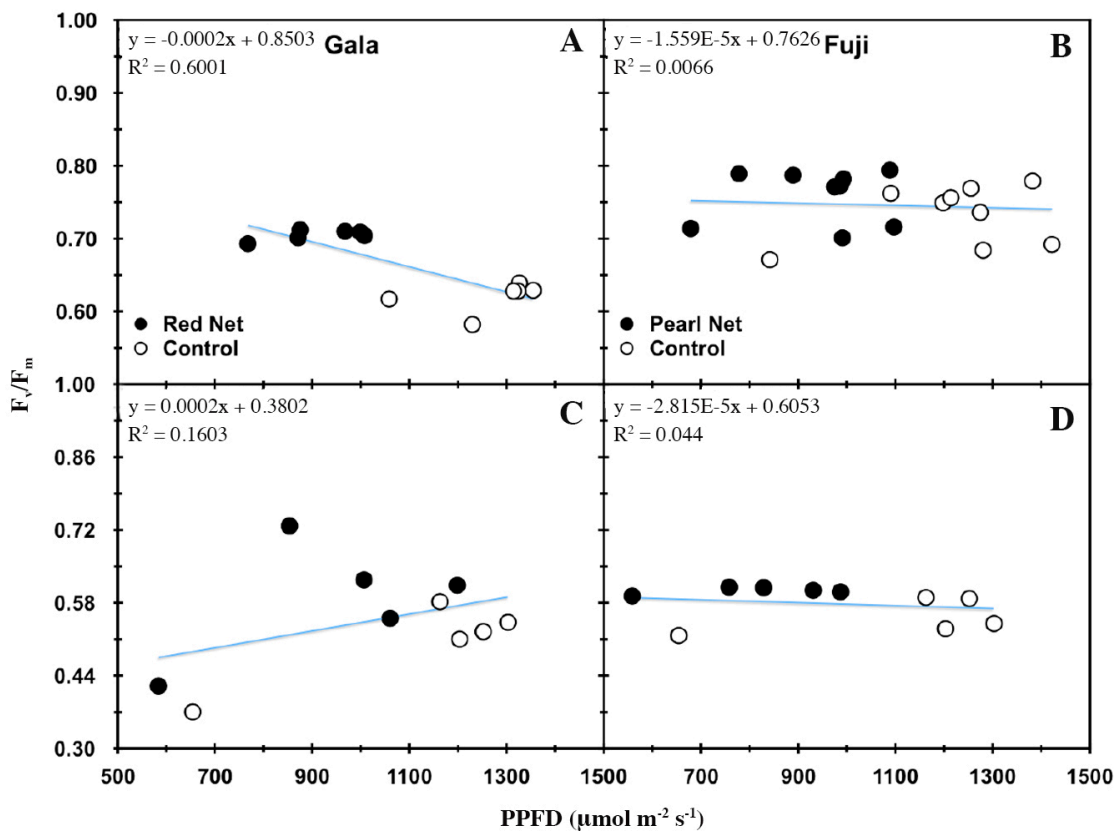

Figure 11. Relationship between maximum photochemical quantum efficiency of photosystem II $\left(F_{\mathrm{v}} / \mathbf{F}_{\mathrm{m}}\right)$ and fruit skin surface temperature measured in the growing season (A and B) and at physiological maturity ( $\mathrm{C}$ and $\mathrm{D}$ ) for netted and non-netted (control) 'Gala' and 'Fuji' fruit.

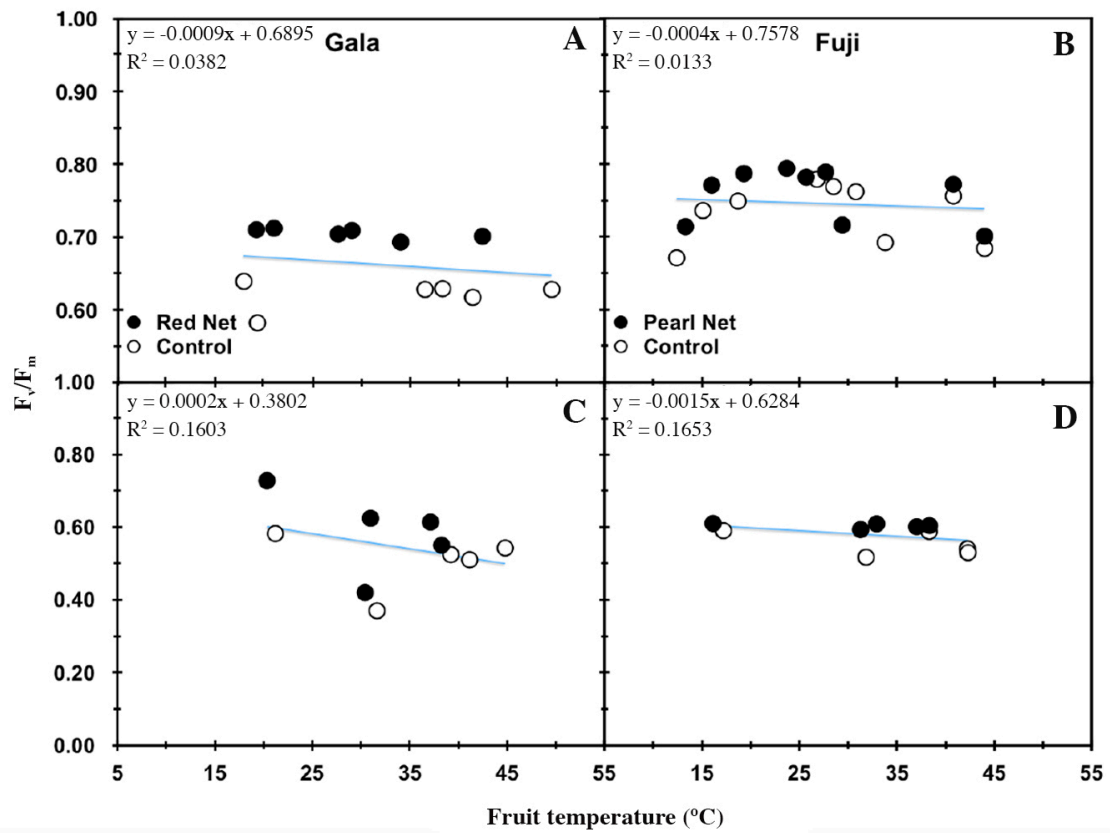


which was up to $49^{\circ} \mathrm{C}$ for the fruit in the non-netted control for 'Gala' (Figure 6C) and $48{ }^{\circ} \mathrm{C}$ for 'Fuji' (Figure 6F). These FST are lower than reported $\left(52^{\circ} \mathrm{C}\right)$ in which is induced severe sun damage with necrosis in apples (Schrader et al., 2009). When we covered the trees with netting, the first thing that was expected were changes in the PPFD, in our research there was a decrease in PPFD between 26\%-29\% in 'Gala' and 21\%-24\% in 'Fuji', with differences between netting and non-netted $(\mathrm{P}<0.05)$ treatments (Figure 4). Netting reduced FST by 2 to $5{ }^{\circ} \mathrm{C}$ in 'Gala' and 2 to $3{ }^{\circ} \mathrm{C}$ in 'Fuji' between treatments (Figure 6), therefore differences in FST could be explained by differences in PPFD transmitted among nets as was reported previously by Iglesias and Alegre (2006). Besides the probably effect of UV light component should be not discarded because during a sunny day netting (regardless the color of net) reduced by 25\%-30\% the UV radiation in comparison to non-netted condition (Figure 5). Previous data of spectral light transmission characteristics of the nets demonstrated that red netting (used in 'Gala' orchard) reduced light transmission in the visible spectra $(400-700 \mathrm{~nm})$, while pearl netting (used in 'Fuji' orchard) did not alter the light transmission in the visible spectra (Umanzor et al., 2017). These differences in the spectral transmission among nets would be explained the differences in the PPFD founded in ours experiments (Figures 4 and 5).

Considering the effect of the netting to reduction of PAR and FST, with less sun damage to the fruit in both cultivars (Figures 4, 5, and 6), it can be inferred that the first mechanism of the netting on sun damage control is related to the reduction in PPFD by interception and light scattering, having a reduction in FST, coinciding with previous findings in which the effect of netting on the fruit was studied (Amarante et al., 2011). Furthermore, the UV light reduction by nets also could be explained the ability of netting to reduce sun damage in apples, demonstrating the role of this component of the light in the sunburn development in apple fruits (Rackso and Schrader, 2012).

As the apple grows and matures on the tree, its transpiration ability noticeably decreases, so that its ability to regulate peel temperature also decreases under extreme solar radiation conditions (Morandi et al., 2012). This occurred in our study with 'Fuji' at 150 DAF (Figure 6F), which recorded the maximum FST for both the non-netted (control) and netted conditions. This has been supported by studies conducted in Chile, where it was demonstrated that damage caused on the peel because of fruit exposure to high temperatures during the production season ( 3 to 4 mo) depends on the cultivar and fruit development stage; therefore, late harvest cultivars, such as 'Fuji', are very sensitive to sun damage near harvest time (Yuri et al., 2004).

Previous studies have reported that a lower incidence of sun damage by using netting is due to lower direct incidental radiation on the fruit combined with the reduction in fruit temperature (Iglesias and Alegre, 2006). For this reason, the use of netting has been promoted in several parts of the world, especially in apple-producing areas with high temperatures and high solar radiation (McCaskill et al., 2016).

Regarding solar radiation, our results demonstrate that PPFD values found in the non-netted treatment significantly contribute to the increase in sun damage with browning of the apple fruit peel for both 'Gala' and 'Fuji'; this is equivalent to the presence of symptoms of slight sunburn (Figure 3) as reported by other studies (Zupan et al., 2014). However, these PPFD thresholds did not cause photo-oxidative sunburn as previously reported by other authors (Felicetti and Schrader, 2009a; Racsko and Schrader, 2012).

Although there are differences in sun damage with netting and the control (Figure 3), these can be explained by differences in PPFD and FST (Figures 4 and 6); the physiological aspects that underlie such differences have not been understood. Chlorophyll fluorescence has been a non-destructive tool widely used to evaluate abiotic and biotic stress in tissue containing chlorophyll, that is, leaves and fruit (Seo et al., 2008). Previous studies have demonstrated that the photochemical efficiency of photosystem II $\left(\mathrm{F}_{\mathrm{v}} / \mathrm{F}_{\mathrm{m}}\right)$ decreases on the peel of apple and tomato fruit exposed to sun damage (Torres et al., 2006; Naschitz et al., 2015), which concurs with the results obtained in the present study (Figure 7). Information to date indicates that this as a consequence of chlorophyll loss in sun-exposed tissue and the malfunction of the photosystem II reaction center when the fruit peel displays damage (Naschitz et al., 2015).

According to Naschitz et al. (2015), the maximum $F_{v} / F_{m}$ value on the apple fruit peel is reached with FST values from 36 to $39{ }^{\circ} \mathrm{C}$, while temperatures greater than $40{ }^{\circ} \mathrm{C}$ (such as the values found in the present study, Figure 6) are responsible for the decrease of $\mathrm{F}_{\mathrm{v}} / \mathrm{F}_{\mathrm{m}}$. Similar results have been reported by Chen et al. (2008) and Wand et al. (2008). Our study revealed that the effect of using netting on FST for 'Gala' and 'Fuji' was $5{ }^{\circ} \mathrm{C}$ and $2{ }^{\circ} \mathrm{C}$ lower, respectively, than in the non-netted treatment (Figure 6), which indicates increases of $12 \%$ and $3 \%$ in $F_{v} / F_{m}$ for these cultivars, respectively (Figure 7). Naschitz et al. (2015) point out that the $F_{v} / F_{m}$ threshold for sun damage to develop 
in apples is approximately 0.1 to 0.2 , which is quite low compared to values found in the present study (Figure 7); these authors concluded that the $\mathrm{F}_{\mathrm{v}} / \mathrm{F}_{\mathrm{m}}$ threshold was more related to the symptoms associated with whitening rather than browning for fruit subjected to high temperature $\left(40\right.$ to $\left.47^{\circ} \mathrm{C}\right)$ conditions and under controlled conditions. This indicates that the $\mathrm{F}_{\mathrm{v}} / \mathrm{F}_{\mathrm{m}}$ threshold values at which sun damage is induced under field conditions differ from those estimated under controlled conditions.

On the other hand, a correlation between photo-inhibition and the decreased $\mathrm{F}_{\mathrm{v}} / \mathrm{F}_{\mathrm{m}}$ relationship has been observed (Torres et al., 2006). We found that $F_{v} / F_{m}$ significantly decreased with the number of hours fruit were exposed to the sun (picked from the tree) at full sun, which was mitigated by using netting (Figures 8 and 9). This could be explained by a higher photo-inhibition level in those fruit that were unable to overcome the stress of being picked from the tree without an appropriate water supply to cool the skin and which will finally develop sunburn symptoms, as shown in fruit picked from the trees and directly exposed to the sun (Racsko and Schrader, 2012).

The $F_{v} / F_{m}$ values on fruit peel under netting for both cultivars were near 0.7 to 0.8 (Figure 7). Wand et al. (2008) compared apple fruit sensitivity to heat; when the FST was near to $38{ }^{\circ} \mathrm{C}$, the $\mathrm{F}_{\mathrm{v}} / \mathrm{F}_{\mathrm{m}}$ remained at 0.7 , indicating that under this FST threshold the PSII activity reached the full recovery. These results indicate a lower fruit photoinhibition under netting with respect to fruits exposed to the direct sun (non-netted), in which the $F_{v} / F_{m}$ values reached up to 0.6. This could probably be explained by the direct effect of PAR reduction. Although this was demonstrated by good correlation found between variations of $F_{v} / F_{m}$ and PPFD for 'Gala', this was not the case for 'Fuji' (Figure 10). There was no close relationship between changes of $F_{v} / F_{m}$ and PPFD for 'Fuji', which indicates that the effect of netting to decrease sun damage in this cultivar is not fully explained by a reduction of solar radiation intensity. It has been demonstrated that when FST increases up to sub-lethal damage in the apple peel the $\mathrm{F}_{\mathrm{v}} / \mathrm{F}_{\mathrm{m}}$ also is reduced by the negative effect of high temperature on electron donation of the oxygen involving complex (OEC) to the PSII reaction center, causing damage in the PSII reaction center of the entire electron transport chain (Chen et al., 2008). Apple fruit has limited capacity to use the PPFD in photosynthesis; therefore, the excess energy must be dissipated as heat through the xanthophyll cycle and by the process called non-photochemical quenching (NPQ) (Racsko and Schrader, 2012). The NPQ mechanism has been mostly described during photo-oxidative damage development, which finally led to lethal sun damage in apples (Racsko and Schrader, 2012). In our experiments, NPQ analyses were not realized and chlorophyll fluorescence parameters were measured fruit that develops no lethal damage (sunburn browning). However, it was clearly demonstrated in our study that netting increased $\mathrm{F}_{\mathrm{v}} /$ $F_{m}$ values in both cultivars for fruit growing on the tree as well as picked fruit (Figures 7, 8, and 9). A decrease in $\mathrm{F}_{\mathrm{v}} / \mathrm{F}_{\mathrm{m}}$ under radiation stress reflects the damage to the photosystem II complex (Qiu and Lu, 2003); this indicates that netting is effective in reducing the photo-inhibition process in sun-exposed apples for the attenuating effect of radiation that significantly contributes to sunburn development on the apple fruit peel (Racsko and Schrader, 2012; Zupan et al., 2014). There are reports for red 'Anjou' pears that show high tolerance when exposed to high incident light and high temperature; however, $\mathrm{F}_{\mathrm{v}} / \mathrm{F}_{\mathrm{m}}$ efficiency was negatively affected under the same conditions (Li and Cheng, 2009). This explains why the effect of netting on an increase in $F_{v} / F_{m}$ can be noticed early (50 and 90 DAF) depending on the cultivar (Figure 7), or at the start of exposure of fruit picked from the tree (Figures 8 and 9), that is, before fruit are completely sun-damaged.

On the other hand, the loss of chlorophyll itself, which is an early event in sun-exposed fruit, normally occurs during fruit maturation, decreases the $F_{v} / F_{m}$ relationship and is not always perceived as sun damage (Ma and Cheng, 2003). The $F_{v} / F_{m}$ values in our study partially decreased during fruit development, including at chlorophyll fluorescence levels not detectable in 'Gala' (Figure 7), independently of the intensity of fruit sun damage, in accordance with Li and Cheng (2008). This is caused by the loss of chlorophyll in apples for cultivars such 'Gala' and 'Fuji'. Similarly, when mature fruit picked from the tree at full sun, 'Gala' exhibited a more pronounced decrease in $F_{v} / F_{m}$ values than 'Fuji' (Figures 8 and 9), but netting attenuated the decrease in both cases. This indicates that aspects such as chlorophyll content or photo-protective pigments, which can change according to the maturity stage of the fruit or cultivar, also somehow influence the effectiveness of netting to reduce the photo-inhibition process in apples (Racsko and Schrader, 2012). 


\section{CONCLUSIONS}

A high solar radiation combined with high temperature decreases the photochemical efficiency of the photosystem-II in apple peel exposed to direct sun, which is mitigated by the use of netting. These results suggest that the effectiveness of netting to control sun damage in apples is related to increase the photosynthetic efficiency on fruit peel by its attenuating effect on excess of light energy and higher fruit temperature.

The chlorophyll fluorescence measurement in fruit under field conditions can be a useful tool for early detection of the development of sunburn in apples. Furthermore, it can more efficiently differentiate the effectiveness of current methods to mitigate this problem, including the use of netting.

\section{REFERENCES}

Amarante, C.V.T., Steffens, C.A., and Argenta, L.C. 2011. Yield and fruit quality of 'Gala' and 'Fuji' apple trees protected by white anti-hail net. Scientia Horticulturae 129:79-85.

Blanke, M.M. 2009. The structure of coloured-hail nets affects light transmission, light spectrum, phytochrome and apple fruit colouration. Acta Horticulturae 817:177-184.

Brunner, J.F., Jones, W., Kupferman, E., Xiao, C-L. Faubion, D., and Tangren, G. 2003. Information from the careful evaluation of packingline culls. p. 1.6. Washington Tree Fruit Postharvest Conference, Wenatchee. 2-3 December 2003. Postharvest Information Network, Washington State University, Pullman, Washington, USA.

Chen, L-S., Li, P., and Cheng, L. 2008. Effects of high temperature coupled with high light on the balance between photooxidation and photoprotection in the sun-exposed peel of apple. Planta 228:745-756.

Dussi, M.C., Giardina, G., Sosa, D., Gonzalez Junyent, R., Zecca, A., and Reeb, P. 2005. Shade nets effect on canopy light distribution and quality of fruit and spur leaf on apple cv. Fuji. Spanish Journal of Agricultural Research 3:253-260.

Felicetti, D.A., and Schrader, L.E. 2009a. Changes in pigment concentrations associated with sunburn browning of five apple cultivars. I. Chlorophylls and carotenoids. Plant Science 176:78-83.

Felicetti, D.A., and Schrader, L.E. 2009b. Changes in pigment concentrations associated with sunburn browning of five apple cultivars. II. Phenolics. Plant Science 176:84-89.

Gindaba, J., and Wand, S.J. 2005. Comparative effects of evaporative cooling, kaolin particle film, and shade net on sunburn and fruit quality in apples. Horticulture Science 40(3):592-596.

Gindaba, J., and Wand, S.J. 2008. Comparison of climate ameliorating measures to control sunburn on 'Fuji' apples. Acta Horticulturae 772:59-64.

Iglesias, I., and Alegre, S. 2006. The effect of anti-hail nets on fruit protection, radiation, temperature, quality and profitability of 'Mondial Gala' apples. The Journal of Applied Horticulture 8:91-100.

Li, P., and Cheng, L. 2008. The shaded side of apple fruit becomes more sensitive to photoinhibition with fruit development. Physiologia Plantarum 134:282-292.

Li, P., and Cheng, L. 2009. The elevated anthocyanin level in the shaded peel of 'Anjou' pear enhances its tolerance to high temperature under high light. Plant Science 177:418-426.

Ma, F., and Cheng, L. 2003. The sun-exposed peel of apple fruit has higher xanthophyll cycle-dependent thermal dissipation and antioxidants of the ascorbate-gluthatione pathway than the shaded peel. Plant Science 165:819-827.

Maxwell, K., and Johnson, G.N. 2000. Chlorophyll fluorescence - a practical guide. Journal of Experimental Botany 51:659-668.

McCaskill, M.R., McClymont, L., Goodwin, I., Green, S., and Partington, D.L. 2016. How hail netting reduces apple fruit surface temperature: A microclimate and modelling study. Agricultural and Forest Meteorology 226:148-160.

Morandi, B., Zibordi, M., Losciale, P., Manfrini, L., Bastías, R.M., and Correlli Grappadelli, L. 2012. Apple and peach: a different role for fruit transpiration. Acta Horticulturae 932:213-218.

Naschitz, S., Naor, A., Sax, Y., Shahak, Y., and Rabinowitch, H.D. 2015. Photo-oxidative sunscald of apple Effects of temperature and light on fruit peel photoinhibition, bleaching and short-term tolerance acquisition. Scientia Horticulturae 197:5-16.

Qiu, N., and Lu, C. 2003. Enhanced tolerance of photosynthesis against high temperature damage in salt-adapted halophyte Atriplex centralasiatica plants. Plant Cell and Environment 26:1137-1148.

Racsko, J., and Schrader, L.E. 2012. Sunburn of apple fruit. Historical background, recent advances and future perspectives. Critical Reviews in Plant Sciences 31:455-504.

Schrader, L.E. 2011. Scientific basis of a unique formulation for reducing sunburn of fruits. Horticultural Science 46:6-11.

Schrader, L.E., Kahn, C.B., and Elfving, D.C. 2009. Sunburn browning decreases at-harvest internal fruit quality of apples (Malus domestica Borkh.) International Journal of Fruit Science 9:425-437. 
Seo, J.H., Sun, J., Schrader, L., and Tian, J. 2008. Use of chlorophyll fluorescence to assess heat stress in apple fruit. Acta Horticulturae 772:279-282.

Solomakhin, A., and Blanke, M.M. 2010. Can coloured hailnets improve taste, consumer appeal and nutritional value of apple fruit? LWT- Food Science and Technology 43:1277-1284.

Torres, C.A., Andrews, P.K., and Davies, N.M. 2006. Physiological and biochemical responses of fruit exocarp of tomato (Lycopersicon esculentum Mill.) mutants to natural photo-oxidative conditions. Journal of Experimental Botany 57:1933-1947.

Umanzor, C., Bastías, R.M., Wilckens, R., and Quezada, C. 2017. Influence of using of pearl and red nets on micro-climate conditions, fruit sun damage and fruit color development in 'Gala' and 'Fuji' apple orchards. Revista Brasileira de Fruticultura 39:930.

Wand, S.J.E., Steyn, W.J., and Theron, K.I. 2008. Vulnerability and impact of climate change on pear production in South Africa. Acta Horticulturae 800:263-271.

Yuri, J.A., Lepe, V., Moggia, C., Bastias, R., and Bertschinger, L. 2004. Sunburn on apple. Schweizer Zeitschrift für Obstund Weinbau 8:7-10.

Zupan, A., Mikulic-Petkovsek, M., Slatnar, A., Stampar, F., and Verberic, R. 2014. Individual phenolic response and peroxidase activity in peel of differently sun-exposed apple in the period favorable for sunburn occurrence. Journal of Plant Physiology 171:1706-1712. 